\title{
Coaching as a support function for potential entrepreneurs
}

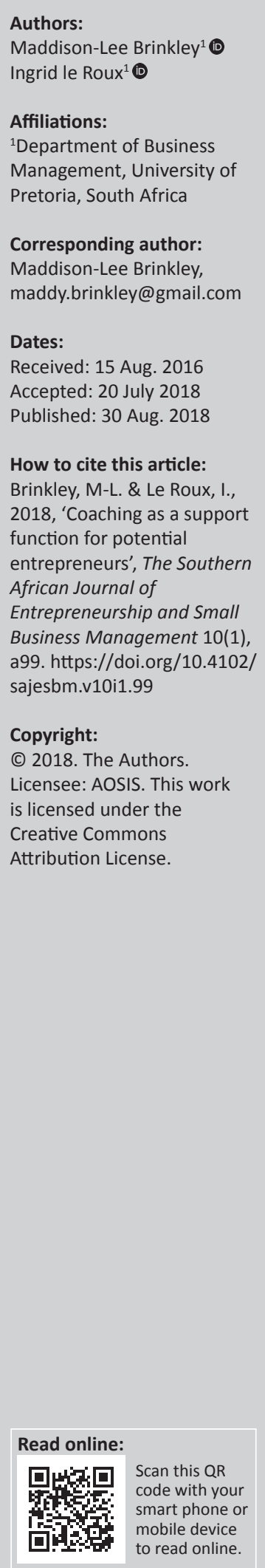

Background: There is a longstanding debate on whether the practice of coaching support is useful for entrepreneurs who lack the skills and assistance needed to make a success of their businesses.

Aim: To gain a better understanding of the benefits derived from coaching support, this study explores the debate on whether coaching is useful as a support function for entrepreneurs.

Setting: Entrepreneurs who participated in a support intervention programme to assist them with the development or growth of their business.

Methods: This study employed a qualitative research design and used 12 semi-structured, face-to-face interviews that were conducted with entrepreneurs from the Pretoria region, who received support intervention for business purposes between August and October 2015.

Results: The study found that confusion still exists around the concepts of coaching and mentoring. Furthermore, it was found that both mentoring and coaching are useful as a support function for entrepreneurs, as evidenced through the benefits derived from the intervention. These benefits mainly include the development of skills, particularly of 21st-century skills, new perspectives, enhanced communication, increased self-awareness and learning, and were facilitated by learning.

Conclusion: Both mentoring and coaching can benefit potential entrepreneurs; however, each form contributes different benefits. Coaching contributes to the self-development of entrepreneurs, whilst mentoring assists in the development of managerial functions needed to successfully start and grow a business. It is clear that these different forms of support intervention aid in developing different skills, and therefore, entrepreneurs should articulate their required needs before engaging support.

\section{Introduction}

It is well documented that entrepreneurial skills are becoming increasingly important for survival and future entrepreneurial and business success as well as job creation. This is especially true in today's dynamic and competitive environment in which entrepreneurs are faced with greater market and competitive pressures (Dobrea \& Maiorescu 2015:249). Entrepreneurs often lack the tools and support needed to grow a successful business and turn to coaching to provide support for the future success of their business (Audet \& Couteret 2012:516; Crompton \& Smyrnios 2011:11). Coaching is used as a support function for entrepreneurs and an important development tool for entrepreneurs (Dobrea \& Maiorescu 2015:248; Fielden \& Hunt 2011:354; Saadaoui \& Affess 2015:56). However, there is little research on the perceived benefits derived from a coaching as a support intervention in the small-to-medium enterprise or emerging entrepreneurial environment (Audet \& Couteret 2012:516; Crompton \& Smyrnios 2011:2; Saadaoui \& Affess 2015:55). Furthermore, it is important to note that previous academic research has explored coaching on a theoretical basis more than on an empirical basis (Kutzhanova, Lyons \& Lichtenstein 2009:195), and more research is needed to investigate the effectiveness of coaching specifically in the entrepreneurship and small and medium-sized enterprises (SME) realm (Kim \& Kuo 2015:169; Mühlberger \& Traut-Mattausch 2015:199).

Coaching is seen as a support function for individual support, based on an interpersonal relationship that facilitates learning (Audet \& Couteret 2012:516; Kutzhanova et al. 2009:207). Literature on coaching also highlights the fact that coaching only provides a support structure and does not to do the work for the entrepreneur (Audet \& Couteret 2012:520). Furthermore, coaching is used as a means to empower the entrepreneur and encourage the entrepreneur to think more strategically and arrive at solutions on their own (Audet \& Couteret 2012:528; Wakkee, Elfring \& 
Monaghan 2010:6). Coaching is thus used in the skills development process and ultimately to improve organisational growth, financial performance and firm performance through derivation of the practical benefits of coaching (Crompton \& Smyrnios 2011:18; Dobrea \& Maiorescu 2015:258; Kutzhanova et al. 2009:195-196). However, literature also outlines the roles of coaching which include coaches acting as sounding boards, listeners, advisors, counsellors, skill enhancers and facilitators of learning and development (Crompton \& Smyrnios 2011:4; Dobrea \& Maiorescu 2015:245). Such roles aid in the processes of development and goal setting and provide focus and direction for entrepreneurial focus on processes and issues relating to their business (Wakkee et al. 2010:7).

Previous research has focused mostly on executive coaching and mentoring rather than business coaching for entrepreneurs (Dobrea \& Maiorescu 2015:248; Koopman 2013:3; Kutzhanova et al. 2009:196). Therefore, it created a platform for a debate on whether coaching is useful in skills development and as a support function for the small-tomedium enterprise, as well as emerging entrepreneurs. The aim of this study was to address and develop a better understanding of the gap that exists in the literature on whether coaching is useful as a support function for entrepreneurs and to better understand the perceived benefits derived from coaching support. The study adds value by contributing to the debate on coaching as a support function and is qualitative in nature. The study aimed to answer the following two research questions, namely:

- What perceived coaching support was received by participants?

- What perceived benefits were derived from the support intervention received?

The rest of the article is structured as follows: Firstly, existing literature that focuses on the entrepreneur, the nature and importance of coaching and the perceived benefits of coaching as a support function is reviewed. A discussion of the methodology with particular reference to the research design, sampling, the data collection method, method of data analysis and the criteria to ensure trustworthiness follows. The findings of this study are then reported and discussed. This section of the paper reports on the participants' reflection on their support intervention experiences. Lastly, the article is concluded with a summary of the findings and theoretical implications, managerial implications, and limitations and recommendations for future research.

\section{Literature review}

\section{The nature and importance of entrepreneurship}

An entrepreneur can be defined as a person who starts a business venture through the identification and exploitation of an opportunity, by gathering resources and bearing the risk of failure (Nieuwenhuizen \& Nieman 2009:9). Similarly, entrepreneurship is a venture undertaken by an entrepreneur who assumes the risk of the discovery and exploitation of an opportunity (Wolf, Kaudela-Baum \& Meissner 2011:243).
Entrepreneurship is important for economic development and performance as it relates to productivity, wealth and job creation, innovation and competitiveness (Adekunle 2011:363; Kuratko, Morris \& Schindehutte 2015:1; Spencer, Kirchhoff \& White 2008:9). However, despite the importance of entrepreneurship, entrepreneurial ventures are susceptible to failure. Entrepreneurial ventures fail because of a lack of business knowledge or learning, poor planning, a lack of appropriate skills, poor management, poor finance management and inability to reach goals (Freiling \& Laudien 2013:2-3; Hammer 2012:3; Urban 2012:17). Entrepreneurs are facing rapid changes in environmental, economic, market and competitive pressures and, because of these pressures, they seek faster and better ways of keeping up with the pace of change (Crompton 2012:22; International Coach Federation n.d.).

Entrepreneurs want to receive advice on matters such as planning, strategy and marketing, and learn how to engage in high-level thinking (Crompton 2012:20). Furthermore, it is essential for entrepreneurs to continuously develop their skill set in the face of changing environmental pressures (Mazra \& Guy 2012:293). Companies are no longer achieving results through traditional management approaches and need to develop inclusive and collaborative working environments. As a result, entrepreneurs seek support to assist them in overcoming these various challenges, improving efficiency, achieving future success and developing necessary skills (Audet \& Couteret 2012:516; Crompton \& Smyrnios 2011:11; International Coach Federation n.d.; Lamine, Mian \& Fayolle 2014:537). Coaching is used by entrepreneurs as a development tool and a mechanism for support that encourages the high-level thinking necessary to be successful in their endeavours now and in the future (Audet \& Couteret 2012:516; Crompton \& Smyrnios 2011:11; Dobrea \& Maiorescu 2015:248; Fielden \& Hunt 2011:354; Saadaoui \& Affess 2015:56).

\section{The nature and importance of coaching}

The notion of coaching is not a new phenomenon. Previous literature highlights definitions of coaching as a means to assist people in developing the necessary knowledge, opportunities and tools needed for adequate growth (Feldman \& Lankau 2005:830). The International Coach Federation (ICF) (n.d.) defines coaching as 'partnering with clients in a thought-provoking and creative process that inspires them to maximize their personal and professional potential'. Similarly, Vidal-Salazar, Ferrón-Vilchez and Cordón-Pozo (2012:424) define coaching as a management practice that encourages personal development and fosters sustainable economic growth. Audet and Couteret (2012:516) offer a conceptualised definition of coaching as a support structure that facilitates learning and development of potential. Other definitions of coaching include coaching as a process of facilitating growth and change (Moore et al. n.d.:33) and coaching as a tool for self-development for increased effectiveness and fulfilment (Centre for Coaching 2015). For the purpose of this paper, coaching is defined as 
the support for emerging entrepreneurs in the start-up phase of their business, with the aim of development or improvement of the necessary skills required for independence and future success (Audet \& Couteret 2012:516; Saadaoui \& Affess 2015:55).

Coaching differs from other managerial tools used to aid the entrepreneur such as consultancy and mentoring. It is important that a distinction be made between these terms. Consultancy does not facilitate learning, unlike coaching which creates and facilitates a learning environment. Coaching does not provide 'ready-made answers to specific problems' (Audet \& Couteret 2012:516) but rather allows and encourages the entrepreneur to overcome problems through their own problem-solving processes (Audet \& Couteret 2012:516; Mühlberger \& Traut-Mattausch 2015:202; Rosha 2013:124). Coaching and mentoring are often used interchangeably in literature (Crompton 2012:33; Koopman 2013:11), owing to the fact that the two methods are almost the same. Both these methods encourage an individual to solve problems themselves (Audet \& Couteret 2012:516). However, mentoring is perceived as a voluntary relationship with a long-term focus on the overall business endeavour. The purpose of mentoring is to assist entrepreneurs in broadening their personal horizons and teaching them how to be an entrepreneur. For the purpose of this paper, mentoring is defined as a formal process of advice or support given by a person who has experience and knowledge to another person who is lacking in such experience and knowledge (Arkün Kocadere 2015:1). Coaching, on the other hand, is perceived as a business relationship with a shortterm focus on assisting entrepreneurs in improving business performance through the development of specific skills and goal achievement, for the purposes of growth and success (Audet \& Couteret 2012:516-517; Crompton 2012:33; Koopman 2013:3; McKevitt \& Marshall 2015:264).

Several types of coaching exist in literature and needs mentioning. These types can be categorised as executive coaching, business coaching, personal coaching and entrepreneurial coaching. However, the focus of this study is on entrepreneurial coaching. Nevertheless, the concept of coaching generally remains the same regardless of the context (Wilson 2014:8). Therefore, for the motivation of this paper, theory was drawn from all contexts to provide supporting arguments.

\section{The roles of the coach}

The roles of coaching, as well as the roles of coaches, are highlighted throughout literature. A coach can perform various roles such as improving job performance, assisting in the development of strategic plans, inspiring entrepreneurs to reach higher levels of personal and professional potential, assisting the entrepreneur in defining his or her limitations, and providing guidance, support, accountability and encouragement (Crompton \& Smyrnios 2011:4; Kutzhanova et al. 2009:207; Lavryk 2013:142; Lawless 2009:41; Rosha 2013:124). The coach provides support that creates the opportunity for an entrepreneur to acquire or enhance skills for specific tasks (Bax, Negrutiu \& Calota 2011:5; Crompton \& Smyrnios 2011:4; Rosha 2013:124), by facilitating learning and development, and assisting an individual in the formation of new strategies for thinking (Bax et al. 2011:5; Crompton \& Smyrnios 2011:4; Kutzhanova et al. 2009:207). The aim is to help the entrepreneur develop the critical ability to step back from a situation and to think about the learning process (Audet \& Couteret 2012:518).

Coaches provide guidance towards a better focus on organisational issues and processes and facilitate change (Botma 2012:7; Wakkee et al. 2010:7) by guiding the entrepreneur into a situation where he or she becomes aware of his or her incompetencies, which becomes necessary for implementing corrective measures. Entrepreneurs are taught to see themselves realistically and reflect on their behaviour and how others perceive their actions, which is achieved through inner potential exploration, learning and selfawareness (Bachkirova, Arthur \& Reading 2015:185; Crompton 2012:28; Lawless 2009:10; Vidal-Salazar et al. 2012:426). The coach provides a structure that does not allow the coach to do work for the entrepreneur, but rather a structure that will facilitate problem-solving and encourage entrepreneurs to derive their own solutions (Audet \& Couteret 2012:516; Koopman 2013:5). This solution-focused approach uses thought-provoking questioning that encourages entrepreneurs to change their thinking by challenging their underlying assumptions and allowing entrepreneurs to work through challenges that they perceive as opportunities rather than as problems (Crompton 2012:50; Crompton, Smyrnios \& Bi 2014:17; Nikolova et al. 2014:86). The coach may act as a sounding board for entrepreneurs with the purpose of challenging their thinking and encouraging more strategic thinking for the exploration of alternative perspectives (Gray, Ekinci \& Goregaokar 2011:864-865). In this way, coaches are expected to listen and create a safe space for sharing and discussion of problems and opportunities (Crompton 2012:150; Nikolova et al. 2014:86).

\section{Perceived benefits of coaching}

Coaching has an important place in the world of business as a useful tool in jobs that require learning (Saadaoui \& Affess 2015:55; Vidal-Salazar et al. 2012:426). However, there is little research on the effect of or usefulness of coaching in the small-to-medium enterprise or emerging entrepreneurial environment (Audet \& Couteret 2012:516; Crompton \& Smyrnios 2011:2; Gray et al. 2011:865; Saadaoui \& Affess 2015:55). However, literature does acknowledge that coaching is effective, specifically because of its ability to meet the unique needs and expectations of entrepreneurs. Coaching increases the effectiveness of improvement procedures, efficiency, development of entrepreneurial behaviours, selfconfidence, capacities, new knowledge and skills and ultimately assists in achieving desired ends (Saadaoui \& Affess 2015:55; Vidal-Salazar et al. 2012:430; Wakkee et al. 2010:3). Entrepreneurs are more open to innovation and 
change within their business, which may be essential for the growth and sustainability of the business (Chaudhry 2015). Other benefits include new perspectives, increased productivity and performance, goal attainment, life and work satisfaction and fulfilment, better quality of work, increased adaptability, enhanced communication, increased self-awareness and increased leadership effectiveness (Centre for Coaching 2015; International Coach Federation n.d.; London Deanery 2014; Mineur 2012:12). Coaching works to execute planning and preparation, define expectations and responsibilities and provide support in an attempt to positively, effectively and permanently influence entrepreneurs and their businesses (Centre for Coaching 2015; Crompton \& Smyrnios 2011:7). Literature further shows that coaching has an important bearing on important factors such as self-efficacy, growth and performance, skills development, goal setting and planning, and personal and work life.

\section{Self-efficacy}

Entrepreneurial self-efficacy refers to the strengths of an individual's belief that he or she has the capability of performing the roles and tasks of an entrepreneur and represents what the individual thinks he or she can realise with his or her skills (Bullough \& Renko 2013:345; Saadaoui \& Affess 2015:56; Urban 2013:6-7). Higher levels of selfefficacy result in higher levels of performance (Bachkirova et al. 2015:179; Wakkee et al. 2010:5). The reason for this is that individuals with higher levels of self-efficacy perceive their environment as having more opportunities and fewer risks, and are more inclined to put more effort into overcoming challenges and achieving their goals (Hechavarria, Renko \& Matthews 2012:689; Urban 2013:4). Self-efficacy increases the competence to identify and discover new opportunities, facilitates learning and contributes to improving the quality of planning and the development of both human and conceptual skills. The entrepreneur develops the capability of overseeing, managing and motivating employees, as well as the capacity to improve working conditions and business performance (Hechavarria et al. 2012:688; Saadaoui \& Affess 2015:59; Urban 2006:3). Self-efficacy can be enhanced as a result of learning facilitated through coaching and includes transferring knowledge and empowering the entrepreneur as a way of enhancing the individual's belief in the possibility of success (Audet \& Couteret 2012:516; Urban 2006:3; Wakkee et al. 2010:6).

\section{Growth and performance}

Business coaching has an impact on the growth and performance of an entrepreneur's business (Crompton et al. 2014:25). Dobrea and Maiorescu (2015:248) demonstrated that a company's growth and financial performance were indeed an outcome of coaching. This is furthermore confirmed in the study conducted by Crompton and Smyrnios (2011:8-18). The participants revealed that between $5 \%$ and $50 \%$ of growth was attributable to coaching. The participants revealed that growth resulted because coaching provided them with the opportunity to consider other perspectives and options. Coaching also contributed wisdom, experience, help and guidance. They concluded that coaching is positively related to growth and performance. Further evidence is offered by The ICF (n.d.), who claims that coaching maximises performance through improvement in business management and improved work performance.

\section{Skills development}

Skills can be viewed as the integration of knowledge and ability, within a perceived environmental area of application (Kutzhanova et al. 2009:194). The concept of skill describes specific abilities of the entrepreneur. Entrepreneurs develop different skills because of different experiences. Skill development involves the transition of knowledge into behavioural processes of learning. Coaching is important in the facilitation of learning to expand the knowledge of entrepreneurs. Additionally, coaching is used as a development tool to teach the entrepreneur how to expand, learn and acquire skills and to develop and refine the skills and capabilities of the entrepreneur (Anzengruber 2015:33; Kutzhanova et al. 2009:194-205; Lawton-Smith 2007:2).

\section{Goal setting and planning}

Participating in coaching is associated with enhanced goal attainment (International Coach Federation n.d.). In the study conducted by Lawless (2009:86-125), participants divulge that goal setting and planning made significant differences to their business. For these participants, planning was a means of prevention to the overreaction to daily events and assisted individuals in the control of their businesses. Furthermore, the study revealed that coaching influences goal planning and achievement. Coaching was used to narrow down goals to provide the entrepreneur with a more specific focus. Mühlberger and Traut-Mattausch (2015:218) supported this notion in their study which reinforced the fact that coaching is effective for goal-related results and further revealed that coaching positively influenced goal attainment, and not only goal setting.

\section{Personal and work life}

Coaching can improve mental health, enhance the entrepreneur's quality of life and increase job satisfaction and fulfilment (Centre for Coaching 2015). Coaching affords entrepreneurs the opportunity to develop a broader perspective of the roles they should fulfill in their businesses and allows them to reflect on their existing knowledge. This reflection reveals limitations in the entrepreneurs' skills and, consequently, their inability to cope with problems. Coaching plays an important role in the self-learning process and includes features such as self-management (Gray et al. 2011:877; Kutzhanova et al. 2009:205). Coaching helps participants manage change and carry out cognitive and emotional tasks, as it allows entrepreneurs to divulge confidential concerns, deficiencies and doubts (Gray et al. 2011:874-877), which is found to be useful for entrepreneurs 
in the reduction of stress or loneliness (Botma 2012:48-55). Success in personal areas of an entrepreneurs' life may provide the entrepreneur with greater organisational focus for long-term success (Gray et al. 2011:874).

\section{Summary of literature review}

It can be assumed that coaching is useful as far as it assists entrepreneurs in improving their self-efficacy; contributes to growth and performance; provides a positive learning environment that facilitates skills development; provides an effective means to planning, goal setting and goal achievement; and provides balance in the personal and work life of entrepreneurs. However, Crompton (2012:169) notes that the benefits derived from coaching are difficult to express in quantifiable terms. Rather than a measure of firm growth, benefits are generally determined by the satisfaction felt by the entrepreneur about the coaching experience and by his or her personal development throughout the process, and outcomes are generally difficult to quantify (Bachkirova et al. 2015:178). Therefore, for the purpose of the study, qualitative data are collected through semi-structured interviews to determine the benefits as perceived by the entrepreneurs.

\section{Methodology}

As a result of the qualitative nature of this research and in order to understand how entrepreneurs interpret, construct and make meaning from their experiences, a generic qualitative research design was applied. This design was useful in developing and understanding the usefulness of coaching support and the benefits thereof. This study also sought to describe the coaching experience from an entrepreneur's perspective and expand the current available knowledge on the usefulness of coaching as a support function (Cooper \& Schindler 2014:15; Vogt 2005:22). The questions included in the discussion guide can be found in Appendix 1.

The unit of analysis in this study was individuals who received support intervention for the purposes of learning and development. The sample consisted of 10 entrepreneurs (incubatees) who had received (perceived) coaching as a support intervention for business purposes from an incubator. An incubator can be defined as an environment that fosters the creation and the development of entrepreneurial businesses (Anholon et al. 2016:66). Two additional participants, who had received life coaching support from a professional coach, were included to form an experimental group. One was also an entrepreneur, whilst the other merely received life coaching. The reason for the inclusion of the experimental group is that the researchers noticed that there was confusion between mentoring and coaching, such that the 10 incubatees had the perception that they were receiving coaching support, but had actually received mentoring support from the incubator, as noted in the findings section of the paper.

A total of 12 individuals from Pretoria participated. Snowball sampling and purposive criterion sampling were employed to identify and specify particular predetermined criteria to be possessed by participants (Guest, Bunce \& Johnson 2006:61; Plano Clark \& Creswell 2015:334; Polit \& Beck 2012:519-523). Participants were chosen based on prior experiences with coaching for business purposes and being an entrepreneur. Twenty-one letters of introduction were sent out to potential participants. Fourteen participants responded. Semi-structured interviews were conducted with 12 of the 14 participants who responded to the invitation to participate.

Thematic analysis was used to systematically identify, organise, analyse and report patterns or themes within the data and allowed the researchers to make sense of the coaching experiences of entrepreneurs (Braun \& Clarke 2006:79, 2012:57). The data were coded by inductively assigning codes or labels to describe text segments of the transcripts. Each code identified was relevant to the research questions. Each theme in this paper can be defined using the sub-themes and respective codes, which reflect any meaningful patterns evident from the data.

\section{Findings and discussion}

The aim of this study was to address and develop a better understanding of the gap that exists in literature on whether coaching is useful as a support function for entrepreneurs and to better understand the benefits derived from the received support intervention. Figure 1 shows the total number of responses that correspond with each theme, as well as the number of coded responses that were contributed by the incubatees and those that were contributed by the experimental group.

The graph shows the main themes that emerged in this research, namely: coaching, mentoring, the confusion between coaching and mentoring, 21st-century skills and learning. Furthermore, the graph also shows the contributions of the incubatees and the experimental group to each theme.

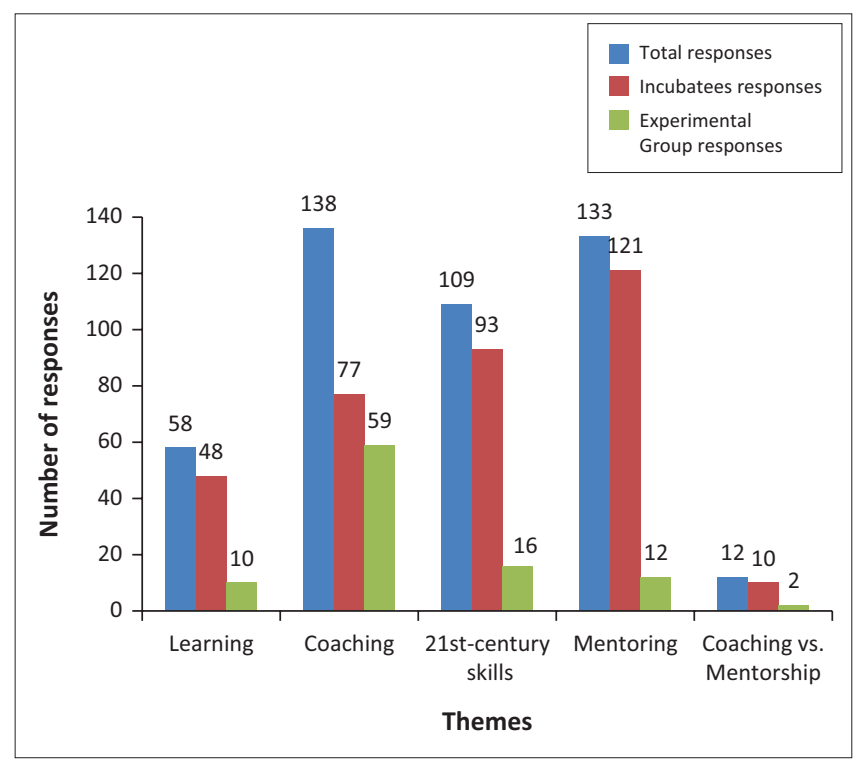

FIGURE 1: Graph showing total coded responses per theme. 
The section following the graph discusses the findings of this research.

\section{Coaching}

The finding in this section deals with the coaching support contribution that participants received. In analysing the 448 coded responses, it was found that 140 were applicable to coaching, which can be described as a self-development tool for increased effectiveness and fulfilment (self-velopment), and as a support intervention that assists in the maximisation of personal and professional development (coaching contribution) (Centre for Coaching 2015; International Coach Federation n.d.). Therefore, the main theme of coaching is supported by the sub-themes of coaching contribution and self-development.

The coaching intervention included participants telling their coach about what was going on in their lives, what they were struggling with and what they were trying to achieve in terms of improvement. In addition to this, and in line with literature, the data showed that coaching was an open conversation that provided participants with a person who listened to them and a safe space where participants were able to speak freely without fear of judgement (Crompton 2012:15; Kim \& Kuo 2015:154; Nikolova et al. 2014:86). The coaching intervention worked to provide direction to participants and empower them through a process of selflearning that allowed them to find their own solutions. This is also in line with literature that suggests that coaching does not merely provide the answer to the problem, but rather allows the individual to derive their own solution (Audet \& Couteret 2012:516; Mühlberger \& Traut-Mattausch 2015: 201-202; O'Flaherty 2003:2; Rosha 2013:124). One participant reported on this process:

'With coaching, it's all about you ... your own steps ... your own outcomes... You are in control ... Not exactly telling you how to do it ... you set your own goals and how you want to go about it, they (the coach) are just there to support.' (P12, female, experimental coachee)

Furthermore, and in line with literature, the intervention revolved around building specific competencies or skills that assisted participants in the discovery of limitations that prevented improvements and developing a self-correcting ability whilst removing self-doubt (Kim \& Kuo 2015:157; Lawless 2009:10; O'Flaherty 2003:2). One participant identified the use of coaching on limiting behaviour:

\footnotetext{
'Receiving coaching ... is actually to get rid of those inhibitions and limitations that limit you to operate at your highest ability.... I realised there was certain ways I acted that was limiting to my business and my behaviour, and through coaching I could remove those.' (P11, male, experimental coachee)
}

Thus, as the literature suggests, self-awareness was created by providing the participants with the opportunity for reflection about limiting behaviours and the effect of such behaviours on those around them (Bachkirova et al. 2015:185; Crompton 2012:28; Lawless 2009:10; Vidal-Salazar et al. 2012:426).
Deriving one's own solutions and increased self-awareness were two reported outcomes of the self-development process experienced by participants. Participants also reported selfdevelopment through increased responsibility and emotional intelligence, improved communication skills and higher levels of confidence, all of which support coaching literature (Bachkirova et al. 2015:185; Mühlberger \& Traut-Mattausch 2015:200; International Coaching Federation n.d.). Participants reported improved confidence on abilities such as risk-taking, decision-making, leadership, talking to people and in one's own capabilities. For example, one participant reported gaining confidence in various ways:

'Confidence in your capabilities.... I am very much confident in the decisions I'm making right now because ... I am well informed.... Before coaching, I'll doubt myself, but now I'm more confident in my leadership skills.' (P12, female, experimental coachee)

Although these findings suggest that coaching is useful as a support function and offers several benefits such as selfdevelopment and increased confidence, it should be noted that 59 out of the 138 coded responses that contributed to the theme of coaching were responses from the two experimental participants (P11 and P12) who received coaching from a qualified coach using a specific growth model to develop the person. This suggests that the group of incubatees were not the recipients of a coaching intervention.

\section{Mentoring}

Mentoring was identified as a second main theme in the study, with a total of 133 coded responses. The three subthemes, namely: structure, mentorship contribution and generic lessons, supplement the definition of mentoring which can be defined as a formal process (structure) of advice or support given by a person who has experience and knowledge to another person who is lacking in such experience and knowledge (mentorship contribution) (Arkün Kocadere 2015:1). In addition, mentoring is focused around teaching entrepreneurs in general and does not address individual-specific needs that teach specific skills (generic lessons) (Audet \& Couteret 2012:516-517). The majority of the participants of the study reported that the formal intervention was an organised and structured process that assisted them with planning and management, developing goals and visions and provided them with focus that they were able to achieve through particular steps. A formal intervention provides such structure (Desimone et al. 2012:104). One participant confirmed that the formal intervention provided structure and assisted in planning:

'... helps you to be organised, to be structured, and to optimise your resources and your talents.... It's (intervention) helped me quantify certain processes in business.... Planning, for example.' (P4, male, incubatee)

The participants also referred to the various characteristics of mentorship that they encountered during the intervention process. These characteristics are evident from literature and included receiving idea feedback and development, 
advice, guidance, encouragement and motivation, and a business world perspective from someone with knowledge and experience (Gordon 2015:7-10; Koopman 2013:3; Mühlberger \& Traut-Mattausch 2015:202; O'Flaherty 2003: $1-3)$. The following quote sums up some of these mentorship characteristics:

'Sharing with us what other successful entrepreneurs that went through this process have done and where they have been ... we see that it's possible ... makes us believe more and become more motivated.' (P6, male, incubatee)

In addition, most of the incubatees reported receiving generic lessons in which they all attended the same classes, and their one-on-one sessions with their mentor followed the same general process. One participant reported that all incubatees received lectures on the following:

'Introduction into the business incubator and then the business model canvas ... on financial stuff like the budget, the statement of financial position and everything, looking at the financial components of the business ... on marketing skills, and then that also further in included presentation skills.' (P3, female, incubatee)

The data suggest that the intervention did not necessarily teach specific skills to address specific needs of the participants. Rather, the intervention taught skills in a more general sense by teaching the participants how to be entrepreneurs and how to start up and run their businesses, unlike coaching, which according to literature, aims to teach specific skills to address specific needs of the participants (Audet \& Couteret 2012:516-517; Centre for Coaching 2015; Crompton \& Smyrnios 2011:7). Almost all the coded responses for this theme were responses from the incubatees. Therefore, it is evident that what the incubatees received was synonymous with mentoring in that they took part in a structured and somewhat generic process, which offered several benefits such as idea feedback and support, encouragement, motivation and advice, in addition to receiving a real business world perspective from individuals with industry experience. Thus, it can be concluded that mentoring played a significant role in teaching the participants what it takes to be an entrepreneur and was therefore useful to the incubatees in this regard. Although the incubatees received mentoring, they referred to the intervention support as coaching; this suggests that there is confusion between the two concepts.

\section{Confusing coaching and mentoring}

Upon analysis of the data, the researchers found that in the open question asked to define coaching and mentoring, it was evident that four of the incubatees were able to describe the terms mentorship and coaching as separate concepts that are in line with the literature. Mentorship is described as a long-term voluntary relationship in which the mentor takes the mentee 'under their wing' to teach the mentee from the mentor's own experience. The focus is on the overall business endeavour, in this case, the endeavour of starting up a business. On the other hand, coaching is described as an intervention with a more short-term focus with the aim of providing individual support and guiding an individual through a thought-provoking process of self-development (Crompton 2012:50; Kim \& Kuo 2015:157; McKevitt \& Marshall 2015:264; O'Flaherty 2003:3). For example, one participant explained this difference:

'Coaching ... is a sort of intimate instruction ... we're talking about a guided experience ... a mentor is someone with industry experience who takes you under the wing to actually teach you the ropes ... they don't do it for a profession.' (P4, male, incubatee)

However, when the incubatees reported on their actual experience of the support intervention they had received, it was evident that some confusion exists. Of the 111 coded responses regarding the support intervention contribution for incubatees, 72 described mentoring experiences whilst only 39 described coaching. These findings support the literature on the confusion between the definitions and the purposes of coaching and mentoring. Generally, there is a lack of consensus about the meaning of coaching and mentorship, and the two terms are often used interchangeably throughout literature (Crompton 2012:33; Koopman 2013:10-11). Six of the incubatees reported that they believed that there was no difference between mentorship and coaching, for example, when asked if participants had different definitions of the two terms, one incubatee said:

'No, I don't think so. I think a mentor and a coach for me would be quite similar.' (P7, male, incubatee)

Interestingly enough, although the four other incubatees could accurately describe the difference between mentorship and coaching, the data suggest that they believe that they had received coaching, when in fact, they mostly received mentoring support. Furthermore, these four incubatees also used the terms interchangeably. The following quote summarises the interchangeable use of coaching and mentoring by an incubatee who was initially able to explain the difference:

'Whether in the form of mentorship or structured coaching ... you require coaching ... we had private sessions with the incubator mentors or coaches.' (P4, male, incubatee)

It can be deduced that there is still some confusion around the difference in meaning of coaching and mentoring support because participants referred to mentorship as coaching and vice versa, even when they believed that they knew the difference. It is possible that confusion stems from the fact that according to participants, the two forms of intervention are almost the same, because both forms of intervention encouraged them to solve problems and do the work themselves. However, according to the literature, coaching differs in the regard that coaching is focused on finding the reason behind the problem (Audet \& Couteret 2012:33; Koopman 2013:4), whilst mentoring in this study places more of a focus on improving business activities. 


\section{Twenty-first-century}

The fourth theme and an unexpected finding that emerged from the coding was that of 21st-century skills. Although participants were not specifically asked about these skills, they were a by-product of the interview conversation. The number of coded responses for this theme totalled 109 responses, making it the third most often occurring theme. As the name suggests, 21st-century skills are the specific skills needed for survival in the 21st century. These skills include creativity, collaboration, critical thinking, communication skills, social and cultural skills, problemsolving, entrepreneurial skills, and information and technological skills (Allen \& van der Velden 2012:12-13; Barell 2010:197; Boyles 2012:42). Participants reported on collaborations, problem-solving, critical thinking and entrepreneurship. These four skills are the sub-themes that make up the main theme of 21st-century skills.

Collaborations result from cooperative encounters that could potentially result in new innovations (Boyles 2012:47-48). Participants reported that they were given the opportunity to share their ideas with other incubatees, with other likeminded individuals at the innovation hub, and with potential investors. Problem-solving requires the identification, interpretation and inquiry (Barell 2010:188; Boyles 2012:51). Participants reported improved decision-making and applying lessons learned during the intervention in their daily lives, for example:

'... now I take informed decisions now, very informed decisions.... So I think I will think things through before I decide, and I will be more objective when I do things.' (P12, female, experimental coachee)

Participants were able to develop entrepreneurial skills and capabilities needed for the success of their business. These skills are essential to entrepreneurial ability and include the ability to better identify opportunities and increase or improve the risk-taking ability to pursue opportunity (Boyles 2012:42; Nieuwenhuizen \& Nieman 2009:9; Wolf et al. 2011:243). Participants reported developing risk-taking ability and the ability to see an opportunity through increased confidence. Finally, critical thinking provides the opportunity to take a step back from a situation and analyse the situation to clarify the learning process (Audet \& Couteret 2012:58; Barell 2010:189). Participants' thinking was challenged in this way so that they think more critically. Critical thinking was developed when participants were given the opportunity to think differently, outside of the box and more realistically. One participant reported that the intervention:

'It helps you to just see past the problem and say: listen, what are we trying to achieve?' (P7, male, incubatee)

However, it seems that because most of the coded responses emerged from the incubatee group, mentoring contributed to the development of 21st-century skills, more than that of coaching. Nevertheless, all participants benefited from the development of several skills regardless of the intervention received. Literature supports the notion that the development of skills is transferred through knowledge that can be expanded by intervention support which facilitates learning (Anzengruber 2015:33; Kutzhanova et al. 2009:194-205; Lawton-Smith 2007:2).

\section{Learning}

Learning was the final theme identified by the researchers. All 12 participants reported learning as an outcome of the intervention. Learning contributed 58 of the responses. Learning is an important reason for seeking support intervention because it assists in decreasing gaps in knowledge and developing or acquiring new skills that will further capabilities (Anzengruber 2015:33; Kutzhanova et al. 2009:194-205; Lawton-Smith 2007:2; Mühlberger \& Traut-Mattausch 2015:200). Participants reported learning from people with experience, learning by expanding their knowledge, learning in a more practical way and repetitive and continuous learning. The following quote reports one participant's reason for seeking support intervention:

'I wanted to learn more on how it is in the field, and not necessarily a textbook.... I can read a textbook, so I wanted to hear from someone in the business.' (P10, female, incubatee)

It is evident that the support that participants received during the intervention process was supplemented by learning, an important development tool for adult learners who were able to broaden their knowledge horizons and develop new skills. The data show that practical learning was achieved through the classroom experience and one-on-one sessions, confirming that adult learners would prefer to learn from someone who has additional insights and experience rather than learn from a textbook. Based on the findings presented above, the researchers concluded that the support intervention resulted in a definite overlap between mentoring, coaching, 21st-century skills and learning. Figure 2 shows the resulting overlap.

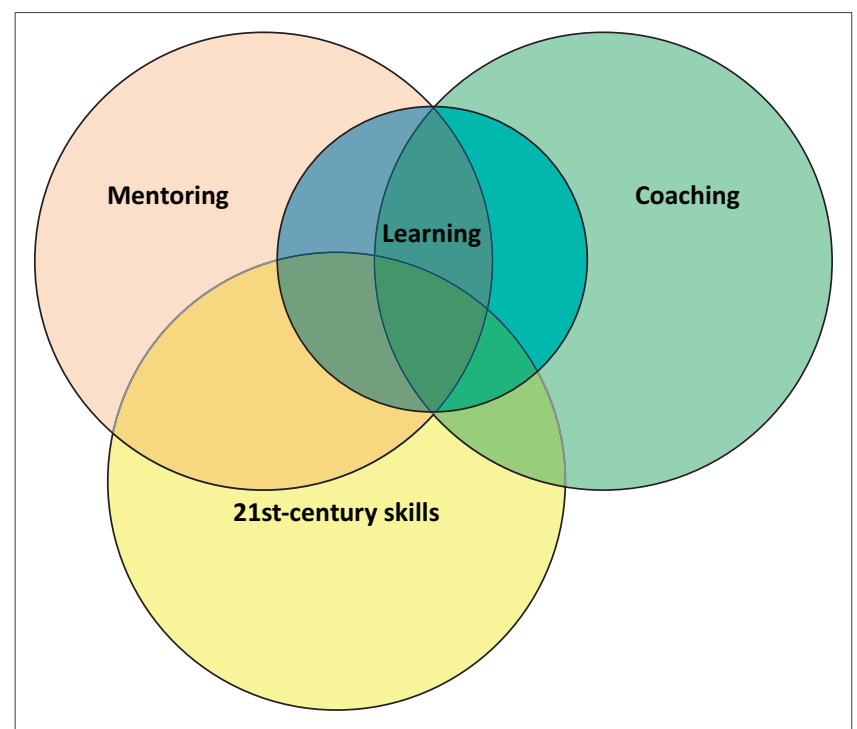

FIGURE 2: Overlap framework. 
The overlap between coaching and mentoring provides evidence that there is a lack of consensus between the two forms of intervention which stems from the confusion in literature and possibly the lack of understanding about the different approaches of the facilitators of the intervention. Furthermore, the overlap also indicates that support intervention programmes may draw from the contexts of other types of support interventions to support or strengthen the process. For example, the 10 incubatees who received mentoring also reported increased confidence and more enhanced emotional intelligence, which are characteristics synonymous with self-development and ultimately coaching. Although coaching and mentoring addressed different issues, both forms of interventions contributed to learning. Learning was achieved through a structured process with a set of steps (mentoring) and through a self-exploration process in which participants took their own steps through the process (coaching). What is interesting is that, all the learning that was gained from the support interventions in this study can be linked to 21st-century skills. The researchers developed the framework shown in Figure 3 to show the link between coaching, mentoring and 21st-century skills, as well as the main benefits reported by the participants.

Another interesting finding in this study is the fact that mentoring, which provided structure that assisted with planning, management and organisation skills through guidance, feedback and motivation from the mentor was largely associated with 21st-century skills, more than that of coaching; this overlap is shown in Figure 2. Mentoring has the ability to quickly transfer and integrate 21st-century skills into an entrepreneurial business (Le Roux 2015:15). Mentoring played a large role in the development of 21st-century skills such as critical thinking, problem-solving, collaborating and entrepreneurial skills, which have become increasingly important for survival in the rapidly changing environment that entrepreneurs are faced with today. Furthermore, and although it was not an intention of the study, the two forms of support interventions contributed to the development of seven of the eight main 21st-century skills. Therefore, the value of coaching and mentoring as support functions in

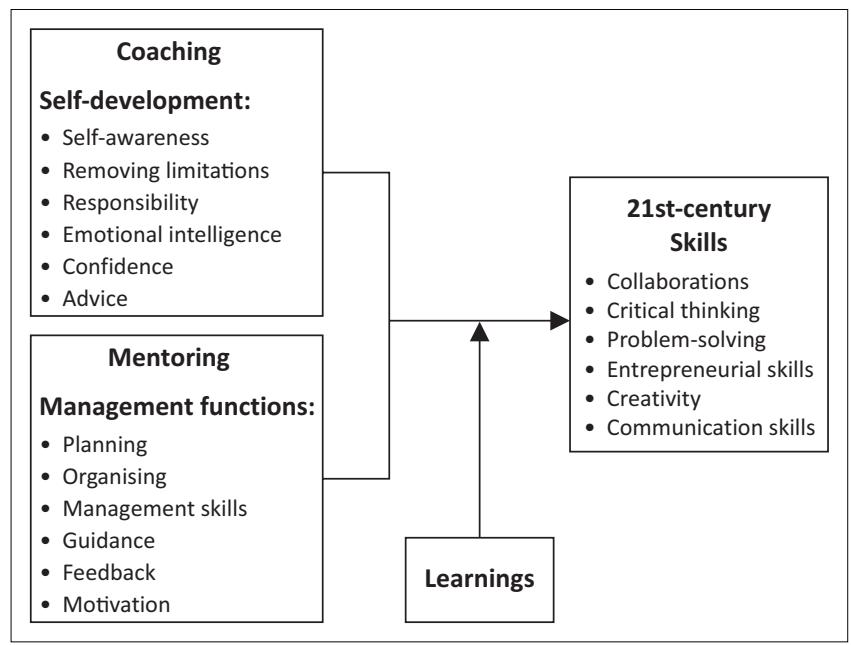

FIGURE 3: Linking framework. assisting start-ups and novice entrepreneurs, linking governmental goals of creating a new business, can no longer be ignored. However, a clear distinction must be made between coaching and mentoring. Furthermore, developing a business without focusing on self-development is not going to be beneficial in creating successful businesses. The role of coaching can no longer be underestimated and therefore incubatee managers should ensure both functions.

\section{Conclusion}

This paper aimed to provide a better understanding of whether coaching is useful as a support function for entrepreneurs and to better understand the benefits derived from the received support intervention. Based on the responses from 12 interviews, the researchers identified five predominant themes by exploring and understanding the support intervention experiences of the participants to determine what perceived coaching support was received. The study discovered that the participants, particularly the incubatees, perceived that they had received coaching support. However, upon comparison to the two participants from the experimental group, it is clear that the incubatees actually had received mentoring support. Therefore, this research offers evidence for the notion that confusion still exists around the concepts of coaching and mentoring (Koopman 2013:3).

In addition, this study found that it was mostly mentoring that facilitated the development of the ever important 21st-century skills. This research illustrated that, regardless of the support intervention, learning was always an outcome, irrespective of whether it was through mentoring, coaching or the development of various skills (Anzengruber 2015:33; Bachkirova et al. 2015:185; Kim \& Kuo 2015:157; Kutzhanova et al. 2009:194-205; Lawton-Smith 2007:2; Mühlberger \& Traut-Mattausch 2015:220). This research provides valuable insight into the various benefits derived from learning that was facilitated by two separate types of support intervention. The study is one of few pieces of research that explored the effectiveness of coaching for entrepreneurs and showed that both coaching and mentoring were useful to the entrepreneurs of this study and has, therefore, contributed to the literature on both coaching and mentoring, the development of 21st-century skills, as well as the resulting overlap that suggests there might be a need for both mentoring and coaching. This study has provided positive evidence regarding the effectiveness of coaching, given the context of the study.

This research shows that intervention is in fact useful as a support function and, therefore, has implications for consultants, managers and practitioners who can use the empirical evidence provided in this study to select an appropriate form of support intervention for either the development of practical skills through mentoring or selfdevelopment through coaching. Furthermore, those who choose to use support intervention should be aware of the various types and different phases of intervention, as they 
serve different purposes and aid in the development of different skills (Bachkirova et al. 2015:178; Koopman 2013:2).

\section{Limitations and recommendations for future research}

There is no study without limitations and it is the case in this study. Firstly, the sample used is not representative of all entrepreneurs who have received support intervention. Secondly, the results from the two participants who received coaching only support the notion that confusion exists amongst the concepts of coaching and mentoring and it cannot be used to generalise the usefulness of coaching as a support function for entrepreneurs. Thirdly, the majority of the participants in this study were in the start-up phase of their businesses, had not yet completed the intervention programme or were still studying. The implication here is that participants were sometimes unsure of the potential benefits of the intervention, because they may not have yet transferred learning developments from the support intervention into their daily business lives. Therefore, future research should consider expanding the selection of participants from other geographical areas and consider exploring the usefulness of the support intervention across different phases of coaching and incubation, for example, before, during and after the intervention (Bachkirova et al. 2015:187; Kim \& Kuo 2015:171; Mühlberger \& TrautMattausch 2015:217-221). Future research should also consider using participants from different incubation programmes to determine whether the derived benefits are consistent across different programmes (Bachkirova et al. 2015:178). Furthermore, more comprehensive research to explore the usefulness of mentoring in the development of 21st-century skills should be considered.

\section{Acknowledgements Competing interests}

The authors declare that they have no financial or personal relationships that may have inappropriately influenced them in writing this article.

\section{Authors' contributions}

I.L.R. was the research supervisor, made conceptual contributions and contributed substantially to the research design, and M.B. made some conceptual contributions, conducted all the interviews and was largely responsible for the preparation and write up of the research.

\section{References}

Adekunle, B., 2011, 'Determinants of microenterprise performance in Nigeria', International Small Business Journal 29(4), 360-373. https://doi.org/10.1177/ 0266242610369751

Allen, J. \& van der Velden, R.K.W., 2012, Skills for the 21st century: Implications for education, ROA, Maastricht University School of Business and Economics, Maastricht University, Netherlands.

Anholon, R., Novaski, O., Pinto, J.S. \& Porto, G.S., 2016, 'Knowledge management in incubated companies: Proposal of a model to enhance managerial skills', International Journal of Knowledge Management Studies 7(1-2), 63-86. https:// doi.org/10.1504/IJKMS.2016.080234
Anzengruber, J., 2015, 'Time perspectives and perceived effectiveness of peer coaching interventions between managers in an organisational context', International Journal of Evidence Based Coaching and Mentoring 9, 30-44.

Arkün Kocadere, S., 2015, 'The development of a scale on assessing peer mentoring at the college level', Mentoring \& Tutoring: Partnership in Learning 23(4):1-13. https://doi.org/10.1080/13611267.2015.1090283

Audet, J. \& Couteret, P., 2012, 'Coaching the entrepreneur: Features and success factors', Journal of Small Business and Enterprise Development 19(3), 515-531. https://doi.org/10.1108/14626001211250207

Bachkirova, T., Arthur, L. \& Reading, E., 2015, 'Evaluating a coaching and mentoring programme: Challenges and solutions', International Coaching Psychology Review 10(2), 175-189.

Barell, J., 2010, 'Problem-based learning: The foundation for 21st century skills', in J. Bellanca \& R. Brandt (eds.), 21st century skills: Rethinking how students learn, Solution Tree Press, Bloomington, IN.

Bax, J., Negrutiu, M. \& Calota, T.O., 2011, 'Coaching: A philosophy, concept, tool and skill', Journal of Knowledge Management, Economics and Information Technology 1(7), 1-9.

Botma, F.J., 2012, 'Development of a coaching framework for the business manager acting in an informal coaching role in the workplace', Doctoral dissertation, Stellenbosch University, Stellenbosch.

Boyles, T., 2012, '21st century knowledge, skills, and abilities and entrepreneurial competencies: A model for undergraduate entrepreneurship education', Journal of Entrepreneurship Education 15, 41-55.

Braun, V. \& Clarke, V., 2006, 'Using thematic analysis in psychology', Qualitative Research in Psychology 3, 77-101. https://doi.org/10.1191/1478088706qp063oa

Braun, V. \& Clarke, V., 2012, 'Thematic analysis', in H. Cooper (ed.), APA handbook of research methods in psychology: Volume 2 Research designs, pp. 57-71, American Psychological Association, Washington, DC.

Bullough, A. \& Renko, M., 2013, 'Entrepreneurial resilience during challenging times', Business Horizons 56(3), 343-350. https://doi.org/10.1016/j.bushor.2013.01.001

Centre for Coaching, 2015, FAQ. [Online], viewed 16 April 2015, from http:// centreforcoaching.co.za/faq/

Chaudhry, A.M., 2015, The advantages and disadvantages of adopting a coaching and mentoring system in an organisation, viewed 16 April 2015, from https://www. academia.edu/9704658/The_advantages_and_disadvantages_of_adopting_a_ coaching_and_mentoring_system_in_an_organization

Cooper, D.R. \& Schindler, P.S., 2014, Business research methods, 12th international edn., McGraw-Hill, New York.

Crompton, B.M., 2012, 'The effect of business coaching and mentoring on small-tomedium enterprise performance and growth', Doctoral dissertation, RMIT University, Melbourne, Australia.

Crompton, B.M. \& Smyrnios, K.X., 2011, 'What difference does business coaching make to entrepreneurs' firm performance and future growth', paper presented at the 56th Annual International Council of Small Business World Conference, Stockholm, Sweden, 15-18th June, pp. 1-20.

Crompton, B.M. \& Smyrnios, K.X. \& Bi, R., 2014, 'Measuring the influence of business coaching on fast-growth firms', Small Enterprise Research 19(1), 16-31. https:// doi.org/10.5172/ser.2012.19.1.16

Desimone, L.M., Hochberg, E.D., Porter, A.C., Polikoff, M.S., Schwartz, R. \& Johnson, L.J., 2014, 'Formal and informal mentoring complementary, compensatory, or consistent?', Journal of Teacher Education 65(2), 88-110. https://doi.org/ 10.1177/0022487113511643

Dobrea, M. \& Maiorescu, I., 2015, 'Entrepreneurial outcomes and organisational performance through business coaching', Amfiteatru Economic 17(33), 247-260.

Feldman, D.C. \& Lankau, M.J., 2005, 'Executive coaching: A review and agenda for future research', Journal of Management 31(6), 829-848. https://doi.org/ future research', Journal of
$10.1177 / 0149206305279599$

Fielden, S.L. \& Hunt, C.M., 2011, 'Online coaching: An alternative source of social support for female entrepreneurs during venture creation', International Small Business Journal 29(4), 345-359. https://doi.org/10.1177/0266242610369881

Freiling, J. \& Lauden, S.M., 2013, 'Explaining new venture failure: A competencebased approach', paper presented at the AIMS International Conference, Nice, France, 11-12th April, pp. 1-7.

Gordon, E.J., 2015, 'Exploring the dyad: Novice physical education teachers' and their mentor's perspectives of the mentoring process', Doctoral dissertation, Texas Tech University, Lubbock, TX.

Gray, D.E., Ekinci, Y. \& Goregaokar, H., 2011, 'Coaching SME managers: Business development or personal therapy: A mixed methods study', The International Journal of Human Resource Management 22(4), 863-882. https://doi.org/10.108 $0 / 09585192.2011 .555129$

Guest, G., Bunce, A. \& Johnson, L., 2006, 'How many interviews are enough: An experiment with data saturation and variability', Field Methods 18(1), 59-82. https://doi.org/10.1177/1525822X05279903

Hammer, M.H., 2012, 'Why entrepreneurs fail and how to fight it?', E-journal Onderzoek voor een vitale Region 1(1), 1-8.

Hechavarria, D.M., Renko, M. \& Matthews, C.H., 2012, 'The nascent entrepreneurship hub: Goals, entrepreneurial self-efficacy and start-up outcomes', Small Business Economics 39(3), 685-701. https://doi.org/10.1007/s11187-011-9355-2

International Coach Federation, n.d., Coaching FAQ's, viewed 16 April 2015, from http://www.coachfederation.org/need/landing.cfm?ltemNumber=978\&navitem Number $=567$ 
Kim, S. \& Kuo, M.H., 2015, 'Examining the relationships among coaching, trustworthiness, and role behaviors: A social exchange perspective', The Journal of Applied Behavioral and role behaviors: A social exchange perspective', The Journal of Applied

Koopman, R.G., 2013, 'Coaching and mentoring entrepreneurs; more definitions won't work', paper presented at 27nd RENT, Vilnius, Lithuania, 20-22 November, pp. 1-14.

Kuratko, D.F., Morris, M.H. \& Schindehutte, M., 2015, 'Understanding the dynamics of entrepreneurship through framework approaches', Small Business Economics 45(1), 1-13. https://doi.org/10.1007/s11187-015-9627-3

Kutzhanova, N., Lyons, T.S. \& Lichtenstein, G.A., 2009, 'Skills-based development of entrepreneurs and the role of personal and peer group coaching in enterprise development', Economic Development Quarterly 23(3), 193-210. https://doi. org/10.1177/0891242409336547

Lamine, W., Mian, S. \& Fayolle, A., 2014, 'How do social skills enable nascent entrepreneurs to enact perseverance strategies in the face of challenges: A comparative case study of success and failure', International Journal of Entrepreneurial Behavior \& Research 20(6), 517-541. https://doi.org/10.1108/ IJEBR-02-2013-0020

Lavryk, A., 2013, 'Business coaching', Development Management (18), 141-142.

Lawless, M., 2009, 'The influence of life coaching on entrepreneurs goal planning and attainment', Doctoral dissertation, Waterford Institute of Technology, Republic of Ireland.

Lawton-Smith, C., 2007, 'Coaching: Is it just a new name for training', International Journal of Evidence Based Coaching and Mentoring 1, 1-9.

Le Roux, I., 2015, The missing link in the 21st century skills debate.

London Deanery, 2014, What are the benefits of coaching and mentoring?, Stewart House, London, viewed 16 April 2015, from http://mentoring.londondeanery.ac uk/our-scheme/overview/what-are-the-benefits-of-coaching-and-mentoring

Mazra, M. \& Guy, O.R., 2012, 'Empirical and explanatory approach of support effect on newly created firms' performance', Journal of Management and Sustainability 2(2), 293-304. https://doi.org/10.5539/jms.v2n2p293

McKevitt, D. \& Marshall, D., 2015, 'The legitimacy of entrepreneurial mentoring', International Journal of Entrepreneurial Behavior \& Research 21(2), 263-280. https://doi.org/10.1108/IJEBR-05-2014-0089

Mineur, M., 2012, 'Determining relevant factors of coaching: The development of a questionnaire', Doctoral dissertation, Tilburg University, Tilburg, Netherlands.

Moore, M., Highstein, G., Tschannen-Moran, B. \& Silverio, G., n.d., Coaching behaviou change, viewed 18 April 2018, from http://downloads.lww.com/wolterskluwer vitalstream_com/sample-content/9780781772624_Moore/samples/ MooreSampChap3.pdf

Mühlberger, M.D. \& Traut-Mattausch, E., 2015, 'Leading to effectiveness comparing dyadic coaching and group coaching', The Journal of Applied Behavioral Science 51(2), 198-230. https://doi.org/10.1177/0021886315574331

Nieuwenhuizen, C. \& Nieman, G., 2009, 'The nature and development of entrepreneurship', in G. Nieman \& C. Nieuwenhuizen (eds.), Entrepreneurship: A South African perspective, 2 nd edn., pp. 1-16, Van Schaik, Hatfield, Pretoria.

Nikolova, N., Clegg, S., Fox, S., Bjørkeng, K. \& Pitsis, T., 2013, 'Uncertainty reduction through everyday performative language work', International Studies of Management \& Organization 43(3), 74-89. https://doi.org/10.2753/IMO0020-8825430305
O'Flaherty, C., 2003, Coaching versus mentoring versus leading versus managing viewed 27 October 2018, from http://www.centreforcoaching.co.za/images/ stories/o_vs_vs.pdf

Plano Clark, V.L. \& Creswell, J.W., 2015, Understanding research: A consumer's guide, 2nd edn., Pearson, Upper Saddle River, NJ.

Polit, D.F. \& Beck, C.T., 2012, Nursing research: Generating and assessing evidence for nursing practice, 9th edn., Wolters Kluwer Health | Lippincott Williams \& Wilkins, Philadelphia, PA

Rosha, A., 2013, 'The similarities and differences between coaching and other targeted interventions', Economics and Business 24, 119-126. https://doi. org/10.7250/eb.2013.015

Saadaoui, S. \& Affess, H., 2015, 'Evaluating the role of coaching on developing entrepreneurial self-efficacy', European Journal of Business and Social Sciences 3(11), 54-61.

Spencer, A.S., Kirchhoff, B.A. \& White, C., 2008, 'Entrepreneurship, innovation, and wealth distribution: The essence of creative destruction', International Small Business Journal 26(1), 9-26. https://doi.org/10.1177/0266242607084657

Urban, B., 2006, 'Entrepreneurial self-efficacy in a multicultural society: Measures and ethnic differences', Journal of Industrial Psychology 32(1), 2-10. https://doi. org/10.4102/sajip.v32i1.22

Urban, B., 2012, 'A metacognitive approach to explaining entrepreneurial intentions', Management Dynamics 21(2), 16-33.

Urban, B., 2013, 'Social entrepreneurship in an emerging economy: A focus on the institutional environment and social entrepreneurial self-efficacy', International Research Journal 11(1), 3-25.

Vidal-Salazar, M.D., Ferrón-Vilchez, V. \& Cordon-Pozo, E., 2012, 'Coaching: An effective practice for business competitiveness', Competitiveness Review: An International Business Journal 22(5), 423-433. https://doi.org/10.1108/ 10595421211266302

Vogt, W.P., 2005, 'Basic research', in W.P. Vogt (ed.), Dictionary of statistics \& methodology, 3rd edn., Sage, Thousand Oaks, CA, viewed 03 June 2015, from http://0-www.srmo.sagepub.com.innopac.up.ac.za/view/dictionary-of-statisticsmethodology/n131.xml?rskey=afvm2A\&row=1

Wakkee, I., Elfring, T. \& Monaghan, S., 2010, 'Creating entrepreneurial employees in traditional service sectors: The role of coaching and self-efficacy', International Entrepreneurial Management Journal 6, 1-21.

Wilson, C., 2014, Performance coaching: A complete guide to best practice coaching and training, Replika Press, India, viewed 19 April 2015, from https://books google.co.za/books?hl=en\&lr=\&id=mNVZAgAAQBAJ\&oi=fnd\&pg=PP1\&dq=Wilso $n,+C .,+2014$,+Performance+coaching:+A+complete+guide+to+best+practice+coa ching+and+training \&ots=vB i1AULSc\&sig=W6ixcdn-HvOoIVPLjcPoF08U9EE ormance $\% 20$ coaching $\% 3 \mathrm{~A} \% 20 \mathrm{~A} \% 20$ complete $\% 2$ gruide $\% 20$ to $\% 2$ best $\% 20$ practice $\% 20$ coaching $\% 20$ and $\% 20$ training $\% 2 \mathrm{C} \& \mathrm{f}=$ false

Wolf, P., Kaudela-Baum, S. \& Meissner, J.O., 2011 'Exploring innovating cultures in small and medium-sized enterprises: Findings from Central Switzerland' International Small Business Journal 30(3), 242-274. https://doi.org/10.1177/ 0266242610386666 


\section{Appendix 1}

\section{Discussion guide: Coaching as a support function for entrepreneurs}

\section{Questions}

I would like to start by asking you a few background questions.

1. What is your definition of an entrepreneur?

2. An entrepreneur is any person who has identified and made an effort to gather resources in an attempt to exploit an opportunity, whilst bearing the risk of failure. Based on this definition, are you an entrepreneur?

3. How long have you been an entrepreneur?

4. Please tell me about your business?

\section{Now I am going to ask you questions about the coaching you have received.}

5. What does the term coaching mean to you?

6. Is your definition of coaching different from your definition of mentorship?

6.1 If yes, please elaborate.

7. What were your reasons for attending coaching?

8. Briefly explain what happened during your coaching sessions.

9. What specific support did you receive from your coach?

10. What is your opinion of the coaching you received?

10.1 Why do you say that?

11. Were the outcomes of coaching in line with your expectations of the process?

11.1 Please elaborate.

12. Tell me about what coaching has taught you.

13. Do you intend to apply what you have learned during coaching in your work environment?

13.1 If yes, please tell me how you will apply what you have learned.

14. What was the most valuable aspect of coaching for you?

15. What aspect of coaching was least valuable to you?

16. Has coaching assisted you with setting goals for your business?

16.1 If yes, were they short-term or long-term goals?

16.2 Please give me an example or two of how coaching has helped in this regard.

17. Has coaching helped you better manage your finances?

17.1 If yes, please elaborate.

18. Has coaching had an effect on your personal life?

18.1 If yes, please elaborate.

19. Has coaching helped you to become a better manager?

19.1 If yes, please elaborate.

20. Has coaching helped you to become more confident in your abilities as an entrepreneur?

20.1 If yes, please elaborate.

21. Has coaching helped you to become a better leader?

21.1 If yes, please elaborate.

22. Imagine that we're 6 months into the future. This coaching has worked very well for you. What will have changed? What will you be doing differently?

23. Was there anything that you disliked about coaching?

23.1 Please elaborate.

24. Were there any aspects of coaching that you feel will not be beneficial to you in your future and the future of your business?

24.1 Please elaborate.

25. What kind of coaching would you like to receive in future?

26. We are now at the end of the interview. Is there anything else you wish to share with me? 